\title{
CARACTERIZAÇÃO DE FAMÍLIAS MUTANTES DE ARROZ PARA TOLERÂNCIA AO FRIO NOS PERÍODOS VEGETATIVO E REPRODUTIVO ${ }^{\left({ }^{1}\right)}$
}

\author{
ANDREZA FIGUEIROLA MARTINS $\left({ }^{2}\right)$; EDUARDO ALANO VIEIRA $\left({ }^{3}\right)$; MAURICIO MARINI KOPP $\left({ }^{2}\right)$; \\ VIVIANE KOPP DA LUZ $\left({ }^{2}\right)$; MARCOS FONTOURA DE CARVALHO $\left({ }^{2}\right)$; JULIANA SEVERO \\ CASTELO BRANCO $\left({ }^{2}\right)$; RENATA PEREIRA DA CRUZ ( $\left.{ }^{4}\right)$; FERNANDO IRAJÁ FÉLIX \\ DE CARVALHO $\left({ }^{2}\right)$; ANTONIO COSTA DE OLIVEIRA $\left({ }^{*}\right)$
}

\begin{abstract}
RESUMO
As temperaturas baixas que ocorrem durante o cultivo do arroz na Região Sul do Brasil causam prejuízos ao rendimento e à qualidade dos grãos de arroz. Genótipos tolerantes a baixas temperaturas seriam uma alternativa para minimizar tais prejuízos. Desse modo, o presente trabalho teve como objetivo avaliar a tolerância ao frio em famílias mutantes de arroz (geração $\mathrm{M}_{4}$ ) nos períodos, vegetativo e reprodutivo, como forma de identificação de variabilidade genética para o caráter. Para a avaliação das famílias mutantes quanto à tolerância ao frio, no período vegetativo, foram utilizadas 10 sementes de cada família colocadas em bandejas celuladas, sendo as plântulas mantidas em casa de vegetação à temperatura de $13{ }^{\circ} \mathrm{C}$ por 10 dias em sala climatizada, com fotoperíodo de 12 horas. A avaliação do período reprodutivo consistiu na aplicação de frio na antese, sendo caracterizada por um estresse de $15^{\circ} \mathrm{C}$ por sete dias. Pelos resultados verificou-se que no período vegetativo, seis famílias tiveram $0-20 \%$ de redução na estatura, com um elevado grau de tolerância. Para o período reprodutivo não foram encontradas famílias com tolerância superior à testemunha diamante.
\end{abstract}

Palavras-chave: Oryza sativa L., melhoramento genético, tolerância a baixas temperaturas, mutação induzida.

\section{ABSTRACT \\ CHARACTERIZATION OF RICE FAMILIES FOR COLD TOLERANCE IN THE VEGETATIVE AND REPRODUCTIVE PHASES}

Low temperatures that occur during the cultivation of rice in the Southern region of Brazil cause reductions in to the yield and quality of the rice grain. Genotypes tolerant to low temperatures would be an alternative to minimize these problems. In the present work cold tolerance was evaluated in rice families $\left(\mathrm{M}_{4}\right.$ generation) in the vegetative and reproductive phases, in order to identify possible genetic variability. For the evaluation in the vegetative stage, 10 seeds from each family were placed in cell trays and kept at $13{ }^{\circ} \mathrm{C}$ for 10 days in controlled chamber with 12 hour day light. The evaluation at the reproductive stage consisted of the application of low temperature at anthesis, by a stress of $15{ }^{\circ} \mathrm{C}$ for 7 days. The results suggest that in the vegetative phase, 6 families presented $0-20 \%$ reduction in stature, showing a high degree of tolerance. For the reproductive phase there were no families showing higher tolerance than the tolerant control.

Key words: Oryza sativa L., plant breeding, induced mutation.

$\left({ }^{1}\right)$ Recebido para publicação em 8 de junho de 2006 e aceito em 11 de dezembro de 2006.

$\left({ }^{2}\right)$ Centro de Genômica e Fitomelhoramento (CGF), Faculdade de Agronomia Eliseu Maciel (FAEM), Universidade Federal de Pelotas (UFPel). E-mail: acostol@terra.com.br

$\left({ }^{3}\right)$ Embrapa Cerrados, Caixa Postal 08223, 73301-970 Planaltina (DF).

$\left({ }^{4}\right)$ Instituto Riograndense do Arroz (IRGA), Porto Alegre (RS). 


\section{INTRODUÇÃO}

Um dos principais fatores que limita o aumento do potencial de rendimento de grãos em arroz no Rio Grande do Sul é a ocorrência de temperaturas baixas, pois plantas de origem tropical como o arroz, são geralmente sensíveis a baixas temperaturas (CRUZ, 2001). A temperatura ideal para o desenvolvimento do arroz situa-se entre $25^{\circ} \mathrm{C}$ e 30 ${ }^{\circ} \mathrm{C}$ (Yoshida, 1981). Temperaturas abaixo desse intervalo podem ocasionar um estresse por frio, o qual é considerado um dos estresses abióticos mais importantes para o arroz. As avaliações da tolerância ao frio em arroz são realizadas sob temperaturas inferiores a $20^{\circ} \mathrm{C}$ nos estádios germinativo, vegetativo e reprodutivo (YosHIDA, 1981; CRUZ, 2001).

A seleção de genótipos tolerantes ao frio nos períodos de desenvolvimento é difícil devido à complexa base genética do caráter e à falta de controle do estresse em condições de campo. Dessa forma, a tolerância ao frio varia conforme o período de desenvolvimento da planta (controle genético diferenciado) (CRUZ, 2001).

Os danos causados pelo frio no estádio de germinação são o atraso e diminuição na porcentagem de germinação. No estádio vegetativo, o frio pode ocasionar atraso no desenvolvimento da planta com redução da estatura, morte das plântulas e amarelecimento das folhas, pois o cloroplasto é diretamente afetado pelas baixas temperaturas causando danos ao aparelho fotossintético e à molécula de clorofila (STHAPIT et al., 1995). No período reprodutivo, os sintomas de danos são má exposição da panícula, esterilidade e manchas nas espiguetas (SouzA, 1990).

Em estudos anteriores, relata-se que o estresse sofrido pelo arroz sob baixas temperaturas é complexo e certamente controlado por mais de um gene (CRUZ e Milach, 2000). No entanto, o murchamento da folha e a clorose, provocadas pelo frio, são de herança simples e controladas pelos genes designados Cts2 e Cts1 (ANDAYA e MackiL, 2003).

A herança da tolerância ao frio no período vegetativo segundo Li e RUTGER (1980) é determinada por quatro ou cinco genes que evidenciam efeitos de dominância e aditividade no controle da expressão do carácter. Já SERAfim (2003) observou em uma população $F_{2}$, vários genes de pequeno efeito atuando no controle genético do caráter.

Os danos mais graves são observados no período reprodutivo (microsporogênese e florescimento). Na microsporogênese o frio ocasiona a esterilidade das espiguetas por meio da inviabilidade do pólen, enquanto no florescimento o frio prejudica a deiscência das anteras e o crescimento do tubo polínico, resultando em uma baixa fecundação das espiguetas (YosHidA, 1981; CRUz e Milach, 2000).

A parte masculina das flores do arroz é mais sensível a baixas temperaturas do que a feminina. $\mathrm{O}$ baixo desenvolvimento do pólen vem sendo apontado como um dos piores danos por frio (KHAN et al., 1986). Em lâminas de água de irrigação, com temperaturas frias, foi observado grande número de espiguetas vazias e essa esterilidade vem sendo atribuída à nãofertilização em conseqüência da indeiscência das anteras ou da imaturidade do grão de pólen (KHAN et al., 1986).

Estudos genéticos revelaram sete ou mais genes envolvidos com tolerância ao frio no período reprodutivo em linhagens derivadas do cruzamento entre cultivares japônicas temperadas, sendo uma sensível ao frio e outra tolerante (TORIYAMA e Futsuhara, 1961). A tolerância ao frio nesse período é controlada por um sistema poligênico com a presença de genes de dominância e aditividade (KHAN et al., 1986).

O objetivo do presente trabalho foi identificar genótipos mutantes de arroz tolerantes ao frio nos períodos vegetativo e reprodutivo.

\section{MATERIAL E MÉTODOS}

\section{Obtenção dos mutantes}

A obtenção das famílias mutantes foi realizada no Centro Regional de Oncologia (UFPel), localizado no município de Pelotas (RS). Os trabalhos tiveram início em 2000, quando foram obtidas as sementes mutantes; nos anos seguintes, foram procedidos os avanços de geração e avaliações para estabelecimento das famílias utilizadas neste estudo.

Sementes de arroz cultivar BRS-7-“Taim” foram irradiadas com raios Gama $\left({ }^{60} \mathrm{Co}\right)$, em aparelho denominado Eldorado 78, com rendimento para um campo de 30 × 30 a $25 \mathrm{~cm}$ da fonte de 37,9 cGy (centigrays) minuto ${ }^{-1}$.

Para obter a dosagem mais adequada, foi desenvolvido um estudo preliminar variando a dosagem para estabelecer o efeito das ondas ionizantes do ${ }^{60} \mathrm{Co}$. Neste estudo, seis tratamentos foram realizados, com as seguintes doses, $0,25,50$, 100, 200, 400 Gy. Cada tratamento foi constituído de uma amostra de 200 sementes que permaneceram em água destilada por uma hora, em seguida foram irradiadas e logo permaneceram por mais uma hora em água corrente. A seguir foram semeadas em 
bandejas de areia e avaliadas quanto à germinação e anomalia no sistema radicular e de parte aérea. Neste estudo foi estabelecida a dose de 250 Gy para a indução de mutação em arroz cultivar BRS-7-“Taim”.

A seguir, 3.000 sementes previamente hidratadas foram irradiadas na dose de $250 \mathrm{~Gy}$, constituindo a população $\mathrm{M}_{1}$. Essas sementes, após lavagem em água corrente por uma hora, foram semeadas em campo experimental para avanço de geração.

\section{Período vegetativo}

Para esse estádio, o experimento foi desenvolvido em casa de vegetação e em sala climatizada pertencentes ao Instituto Rio Grandense do Arroz, em Cachoeirinha (RS), em outubro de 2004. Foram utilizadas 10 sementes de cada uma das 332 famílias $\mathrm{M}_{4}$ de arroz e das testemunhas BRS 7 Taim (sensível), Irga 420 (sensível) e Diamante (tolerante) (CRUZ, 2001). Primeiramente, as sementes foram colocadas para germinar a uma temperatura de $28^{\circ} \mathrm{C}$ por três dias. Posteriormente, as plântulas foram transplantadas para bandejas com 25 células individualizadas, contendo solo coletado no campo e adubado conforme as recomendações da cultura do arroz irrigado. As bandejas foram mantidas em casa de vegetação a $28^{\circ} \mathrm{C}$ até as plântulas ficarem com três folhas, quando foram transferidas para sala climatizada com temperatura de $10^{\circ} \mathrm{C}$ e fotoperíodo de 12 horas por 10 dias.

Após 10 dias de frio, as plântulas foram avaliadas quanto à estatura (EST1) e levadas para a casa de vegetação, onde permaneceram por mais sete dias à temperatura de $28{ }^{\circ} \mathrm{C}$; após esse período, foi realizada novamente a medida da estatura (EST2) e determinado o número de plantas vivas, intermediárias e mortas dentro de cada família e das testemunhas.

O caráter estatura foi avaliado, medindo-se a distância da base da planta até a ponta da folha mais longa (folha bandeira), em centímetros. A diferença entre a estatura 2 (EST2) e a estatura 1 (EST1) foi estimada, e exprime a capacidade das plântulas em retornar o crescimento vegetativo a $28{ }^{\circ} \mathrm{C}$, após o estresse por frio. O crescimento vegetativo (estatura 2 - estatura 1) das famílias mutantes e das testemunhas sensíveis foi expresso como a porcentagem do obtido para a testemunha tolerante para a avaliação do frio neste período, conforme a seguinte fórmula:

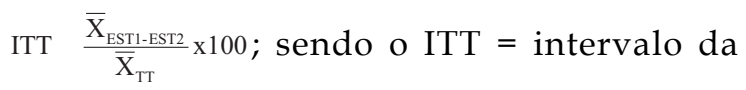

testemunha tolerante, $\overline{\mathrm{X}}_{\mathrm{EST1} 1 \text {-EST2 }}$ (média d-a estatura 2 - a estatura 1) $)_{\text {TT }}$ média da testemunha tolerante.
A avaliação realizada para plantas vivas, mortas e intermediárias dentro de cada família e das testemunhas, foi efetuada por meio da contagem das 10 plantas dentro das famílias mutantes e das testemunhas. As plantas que estavam com duas ou mais folhas verdes foram consideradas vivas, as que desenvolveram uma ou duas folhas bem verdes ou mais de duas com ápices queimados foram consideradas intermediárias e as plantas que ficaram totalmente secas foram consideradas mortas.

\section{Período reprodutivo}

Para a avaliação da tolerância ao frio no período reprodutivo foram selecionadas 49 famílias mutantes da geração M4, e utilizadas como testemunhas as cultivares BRS 7 Taim (sensível), Irga 420 (sensível) e Diamante (tolerante) (CRUZ, 2001).

O experimento foi desenvolvido em casa de vegetação e em sala climatizada pertencentes ao Instituto Rio Grandense do Arroz, em Cachoeirinha, no Estado do Rio Grande do Sul, em novembro de 2004. Foram utilizadas oito sementes de cada uma das 49 famílias M4 e das cultivares testemunhas BRS 7 Taim, Irga 420 e Diamante, as duas primeiras consideradas sensíveis ao frio e a última, tolerante. As sementes foram colocadas para germinar em papel plissado e levadas para câmara de germinação durante quatro dias; quando o coleóptilo estava mais ou menos com $4 \mathrm{~cm}$, essas foram transplantadas para copos plásticos de $500 \mathrm{~mL}$, contendo solo coletado no campo e adubado conforme as recomendações da cultura do arroz irrigado. Foi utilizada uma planta por copo, totalizando oito plantas por família/ genótipo. Aos 40 dias da emergência, foi realizada adubação com $2 \mathrm{~g}$ de uréia.

Foram efetuados desbastes das plantas deixando apenas o colmo e a panícula principal. A temperatura utilizada para as avaliações da reação dos genótipos ao frio foi de $15^{\circ} \mathrm{C}$ aplicada no estádio de antese com duração de sete dias. Em cada família foram mantidas plantas permanentemente na casa de vegetação para servirem como controle. O estádio de antese foi considerado a partir do início da exposição da panícula e as flores abertas foram eliminadas.

Os copos foram levados à sala climatizada com temperatura constante de $15^{\circ} \mathrm{C}$ e fotoperíodo de 9 horas/15 horas; após o período determinado de frio, foram colocadas de volta na casa-de-vegetação. A radiação utilizada na casa de vegetação foi constituída por lâmpadas fluorescentes e incandescentes. As panículas foram colhidas individualmente na maturação e, posteriormente, avaliadas quanto à porcentagem de fertilidade das espiguetas. 
Para a porcentagem de redução de espiguetas foi realizada a contagem total de grãos a $15^{\circ} \mathrm{C}$ e a $28^{\circ} \mathrm{C}$, conforme a seguinte fórmula:

\%REDUÇ̃̃O $\frac{\overline{\mathrm{X}}_{\mathrm{TC}} 15}{\overline{\mathrm{X}}_{\mathrm{TC}} 28}$; sendo $\overline{\mathrm{X}}_{\mathrm{TG}} 15 \mathrm{C}$ média do total de grãos a $15{ }^{\circ} \mathrm{C}, \overline{\mathrm{x}}_{\mathrm{TG}} 28 \mathrm{C}$ média do total de grãos a $28^{\circ} \mathrm{C}$.

Para a porcentagem de espiguetas férteis, foi realizada a contagem de grãos cheios a $15{ }^{\circ} \mathrm{C}$ e a 28 ${ }^{\circ} \mathrm{C}$, conforme a seguinte fórmula:

\%REDUÇÃO $\frac{\overline{\mathrm{X}}_{\mathrm{GC}} 15}{\overline{\mathrm{X}}_{\mathrm{GV}} 28} \times 100$; sendo $\overline{\mathrm{X}}_{\mathrm{GC}} 15 \mathrm{C}$ média de grãos cheios a $15{ }^{\circ} \mathrm{C}, \overline{\mathrm{X}}_{\mathrm{GV}} 28 \mathrm{C}$ média de grãos cheios a $28^{\circ} \mathrm{C}$.

Para o intervalo da testemunha tolerante, os dados de fertilidade para as famílias mutantes e testemunhas sensíveis foram expressos como porcentagem da testemunha tolerante, conforme a seguinte fórmula:

ITT $\frac{\overline{\mathrm{X}}_{\mathrm{EF}}}{\overline{\mathrm{X}}_{\mathrm{EFTT}}} \times 100 ;$ sendo o ITT = Intervalo da testemunha tolerante; $\overline{\mathrm{X}}_{\mathrm{EF}}$ média das espiguetas férteis das famílias mutantes ou das testemunhas sensíveis; $\bar{X}_{\text {EFTT }}$ média das espiguetas férteis da testemunha tolerante.

Os dados de ambos os períodos de avaliação foram submetidos à análise da variância e realizada distribuição de freqüências para as famílias avaliadas.

\section{RESULTADOS E DISCUSSÃO}

Nos dados houve variação significativa para ambos os períodos de avaliação em todas as variáveis analisadas. Para o período vegetativo, a porcentagem de plantas vivas, em relação às 332 famílias, foi de 199 famílias entre 0 e $20 \%$, 54 famílias entre $21 \%$ e $40 \%$; 30 famílias entre $41 \%$ e $60 \%$; 27 famílias entre $61 \%$ e $80 \%$ e 22 famílias entre $81 \%$ e $100 \%$ (Figura 1a). Na porcentagem de plantas intermediárias, observaram-se 57 famílias entre 0 e $20 \%$, entre $21 \%$ e $40 \%$, 51 famílias; entre $41 \%$ e $60 \%$, 67 famílias; entre $61 \%$ e $80 \%$, 79 famílias e entre $81 \%$ e $100 \%$, 78 famílias mutantes M4 (Figura 1b). Para porcentagem de plantas mortas, foram observadas entre 0 e $20 \%$, 300 famílias; entre $21 \%$ e $40 \%$, 18 famílias; entre $41 \%$ e $60 \%$, seis famílias; entre $61 \%$ e $80 \%$, duas famílias e entre $81 \%$ e $100 \%$, seis famílias (Figura 1c).

Entre as três classes avaliadas nas famílias mutantes, a classe com o maior número de famílias foi a de comportamento intermediário, cujas 200 famílias ficaram entre $60 \%$ e $100 \%$ de plantas com uma ou duas folhas bem verdes, ou mais de duas com ápices queimados. Na classe de plantas vivas foram observadas 65 famílias com $60 \%$ a $100 \%$ de plantas vivas, enquanto na classe de plantas mortas, apenas 9 famílias permaneceram entre $60 \%$ a $100 \%$. Relacionando as classes avaliadas com os genótipos testemunhas, observou-se na cultivar BRS 7 Taim 90\% de plantas de comportamento intermediário e $10 \%$ de plantas mortas. Na cultivar Irga 420, verificaram-se $50 \%$ de plantas de comportamento intermediário e 50\% de plantas mortas, e na testemunha tolerante (Diamante) $60 \%$ de plantas vivas e $40 \%$ de plantas intermediárias.
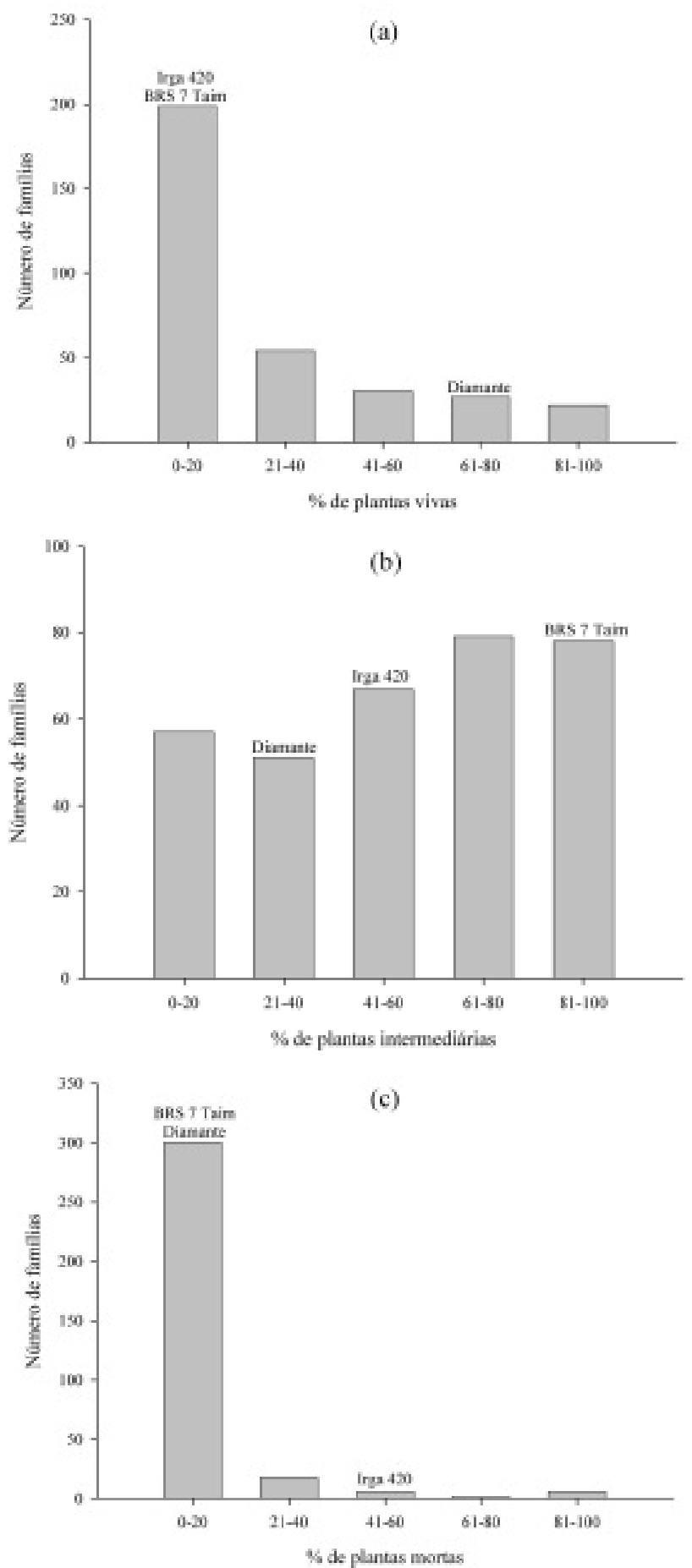

Figura 1. Distribuição de freqüência para porcentagem de plantas (a) vivas, (b) intermediárias e (c) mortas de famílias $\mathrm{M}_{4}$ de arroz originárias da cultivar BRS 7 Taim, após exposição a estresse por frio. FAEM/UFPel, 2006. 
As famílias com $60 \%$ de plantas vivas foram consideradas como tolerantes ao frio nesta avaliação, pois ocorreu comportamento similar à testemunha diamante. Nas testemunhas sensíveis não se observaram plantas vivas, somente intermediárias ou mortas.

Comparando a porcentagem (\%) da estatura relativo à testemunha tolerante constatou-se que seis famílias situaram-se na classe de 0 a $20 \%$, 9 famílias entre $21 \%$ e $40 \%$, 47 famílias entre $41 \%$ e $60 \%, 106$ famílias entre $61 \%$ e $80 \%$, 99 famílias entre $81 \%$ e $100 \%$, 52 famílias entre $101 \%$ e $120 \%$, oito famílias entre 121 e $140 \%$ e acima de $140 \%$, cinco famílias (Figura 2). Dentre as 332 famílias de mutantes avaliadas, $18 \%$ (62 famílias) tiveram crescimento até $60 \%$ da testemunha tolerante (Figura 2), sendo mais sensíveis que as testemunhas sensíveis, enquadrandose no intervalo de $61 \%$ a $80 \%$. Mais da metade das famílias se concentrou nos intervalos de $61 \%$ a $80 \%$ (106 famílias) e $81 \%$ a $100 \%$ (99 famílias), comportando-se de forma similar e superior às testemunhas sensíveis, respectivamente. Em um total de 65 famílias $(20 \%)$ houve crescimento vegetativo superior à testemunha tolerante, sugerindo elevada tolerância ao frio nessa fase de desenvolvimento.

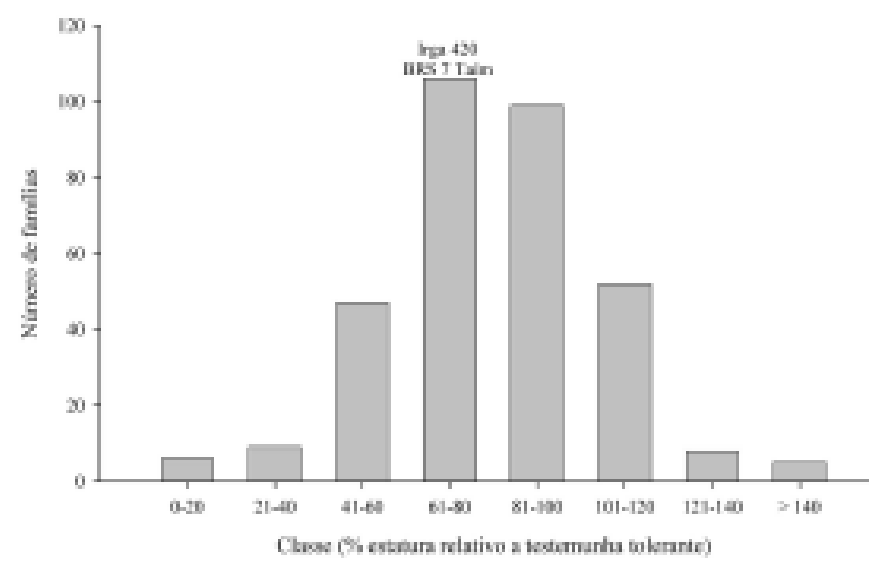

Figura 2. Distribuição de freqüência para o intervalo da porcentagem (\%) de estatura relativo à testemunha tolerante ao frio (cultivar Diamante) em famílias $\mathrm{M}_{4}$ de arroz originárias da cultivar BRS 7 Taim, após exposição a estresse por frio. FAEM/UFPel, 2006.

Os danos causados por temperaturas baixas nesse período são: redução da clorofila (em função de danos do sistema fotossintético) e estatura de plantas (em função da diminuição na divisão e elongação celular). Em estudo realizado por Cruz (2001), concluiu-se que o frio teve maior influência na coloração das folhas do que na estatura de plantas.
No período vegetativo, CRUZ (2001) avaliou a redução da clorofila em que se constatou que das duas avaliações realizadas no período vegetativo, as maiores reduções na clorofila foram observadas na segunda avaliação. Essas reduções foram verificadas para a maioria dos genótipos e os danos fotossintéticos aumentaram mais quando retornaram à temperatura normal.

A redução da estatura foi maior na primeira avaliação, sugerindo que após a ocorrência de temperaturas frias, ao voltar para a temperatura ideal de cultivo, as plantas podem crescer normalmente. Em experimento desenvolvido em uma população de plantas F2, tanto no período germinativo quanto no vegetativo, foram constatados resultados semelhantes aos aqui relatados (SERAFIM, 2003).

Por meio da medida da estatura de plântula, com uma temperatura de $18^{\circ} \mathrm{C}$ por 14 dias foram observados por Li e RUTGER (1980) de 4 a 5 genes com efeitos de dominância e aditividade, como responsáveis pelo controle do caráter.

Neste experimento, notou-se na estatura das plantas uma distribuição continua variando de 18,5 $\mathrm{cm}$ a $117,4 \mathrm{~cm}$; na cultivar tolerante japônica (diamante) observou-se estatura de $98,4 \mathrm{~cm}$ e na cultivar sensível indica (IRGA 420), 87,5 cm.

Para a porcentagem de redução da espigueta, enquanto na cultivar tolerante diamante ocorreu redução de $40 \%$ a $60 \%$, em uma família foi de $60 \%$ a $80 \%$ e, na maioria das famílias, de $80 \%$ a $100 \%$ de redução (Figura 3). Para o caráter porcentagem de espiguetas férteis relativo à testemunha tolerante, as 49 famílias avaliadas foram altamente sensíveis ao frio, enquadrando-se no intervalo de 0 a $20 \%$ da fertilidade obtida para a testemunha tolerante (Figura 4), juntamente com as duas testemunhas sensíveis. Em relação ao caráter porcentagem de redução na fertilidade das espiguetas, CRUZ (2001) observou a maior sensibilidade ao frio no período da antese.

Cruz (2001), em seus estudos, observou também que no período reprodutivo aos três dias de frio não foram notadas diferenças; a única exceção está no genótipo diamante que foi mais afetado no estádio de antese, enquanto aos cinco dias ocorreram diferenças entre os genótipos estudados. No período reprodutivo, o de microsporogenese foi o mais sensível a baixas temperaturas, discordando dos resultados relatados por CRUZ (2001), cujo período mais sensível foi o da antese. Esse fato pode ter ocorrido devido à medida usada ser a distância entre as aurículas da folha bandeira, e os afilhos podem estar adiantados ou atrasados, visto que esse parâmetro é diferenciado para cada genótipo (Yoshida, 1981). 


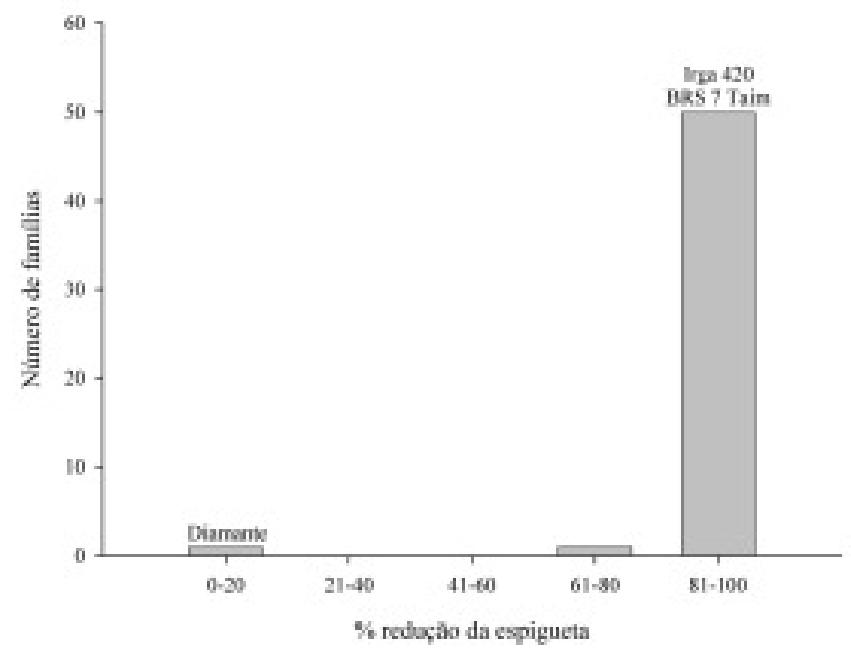

Figura 3. Distribuição de freqüência para a porcentagem de redução das espiguetas, em função do estresse por frio em famílias $\mathrm{M}_{4}$ de arroz originárias da cultivar BRS 7 Taim, após exposição a estresse por frio. FAEM/ UFPel, 2006.

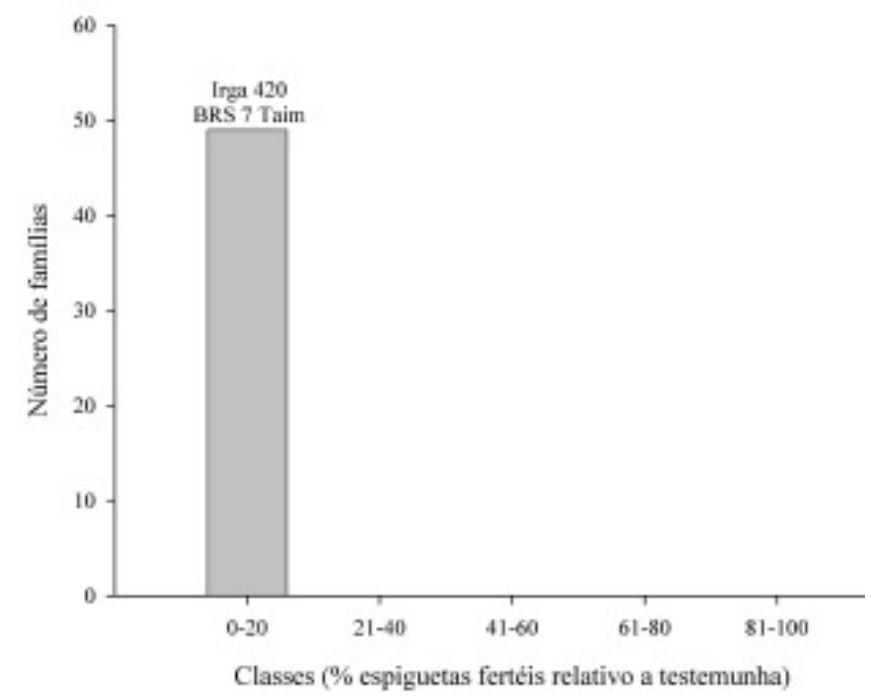

Figura 4. Distribuição de freqüência da porcentagem de espiguetas férteis relativo à testemunha tolerante ao frio (cultivar Diamante) em famílias $M_{4}$ de arroz originárias da cultivar BRS 7 Taim, após exposição a estresse por frio. FAEM/UFPel, 2006.

$\mathrm{Na}$ porcentagem de redução relacionada com a esterilidade das espiguetas, foi constatado por cruz (2001) que a cultivar BRS 7 Taim não diferiu entre os estádios pois foram observadas altas reduções na fertilidade, tanto no estádio de antese quanto no de microsporogênese. Comprova-se que a cultivar BRS 7 Taim tem elevada sensibilidade ao frio nesse período, visto que foram avaliadas famílias mutantes originárias desta cultivar, não sendo possível notar nenhuma tolerância. Entretanto, nos outros dois períodos avaliados, houve famílias que apresentaram tolerância tanto no período de germinação (MARTINS et al., 2005) quanto no vegetativo com comportamento superior à cultivar BRS 7 Taim.

A influência da duração do frio sobre a redução da fertilidade é genótipo dependente, sendo o período crítico observado com dez dias de frio para os genótipos considerados tolerantes e períodos mais curtos para os genótipos sensíveis (CRUZ, 2001). Em estudos sobre redução da fertilidade da espigueta, foram observadas para a cultivar BRS 7 Taim reduções tanto na antese quanto na microsporogênese, com apenas três dias de frio, enquanto para os outros genótipos também considerados sensíveis, uma esterilidade foi notada a partir de sete dias (CRUZ, 2001). Os resultados obtidos, utilizando sete dias de frio, permitiram boa diferenciação dos genótipos nas classes de tolerantes e sensíveis para a variável \% de redução da espigueta, no entanto afetou muito drasticamente a variável \% de espiguetas férteis.

A intensidade da temperatura é um fator importante na determinação do maior ou menor dano às plantas. Em trabalhos sobre condições controladas vêm sendo utilizadas temperaturas variáveis entre o dia e a noite (Lin e PETERson, 1975) ou temperatura constante, que varia de 10 a $20{ }^{\circ} \mathrm{C}$ (Lin e Peterson, 1975; Khan et al., 1986). Para a escolha da temperatura ideal deve-se levar em conta a intensidade do estresse em condições de campo. Também é importante salientar que temperaturas mais baixas permitem identificar maiores níveis de tolerância e temperaturas mais altas em níveis mais moderados de tolerância (BERTIN e BOUHARMONT, 1997).

A duração do estresse é de extrema importância, pois temperaturas de $12{ }^{\circ} \mathrm{C}$ podem não induzir esterilidade quando ocorrerem apenas dois dias de frio e por outro lado podem induzir $100 \%$ de esterilidade quando a exposição de frio for superior a seis dias (Yoshida, 1981). A esterilidade das espiguetas também podem ocorrer com temperatura superior a $20{ }^{\circ} \mathrm{C}$, quando ocorrer exposições muito longas (Nishiyama, 1984). Desta forma, a intensidade da temperatura e sua duração são determinantes para a esterilidade das espiguetas. É possível que tenha sido utilizada temperatura muito baixa $\left(15^{\circ} \mathrm{C}\right)$ ou durante um intervalo de tempo muito grande (7 dias), pois não foi determinado nenhum genótipo com elevada tolerância no período reprodutivo. No entanto, deve-se destacar que o genótipo Diamante (testemunha tolerante) manteve elevado rendimento de espiguetas férteis sob tais condições indicando realmente não haver famílias com tolerância ao frio no período reprodutivo. 
Embora, nas condições do Rio Grande do Sul, temperaturas extremas não sejam comuns durante $o$ período de cultivo da cultura, a ocorrência de anticiclones polares propicia temperaturas inferiores a $15{ }^{\circ} \mathrm{C}$ nos meses de janeiro e fevereiro, podendo causar decréscimos de $25 \%$ a $50 \%$ do rendimento de grãos (Terres et al., 1994; SteinMETZ, 2004).

Os danos causados por temperaturas baixas como má exposição da panícula e fertilidade das espiguetas devem ter bases fisiológicas distintas, na primeira, o efeito decorre da divisão e elongação celular e na segunda sobre os processos de formação e germinação do grão de pólen (YOSHIDA1981; MACKILL et al., 1996).

\section{CONCLUSÃO}

A indução de mutação com Co60 na dose de 250 Gy acético na cultivar de arroz BRS 7 "Taim" gerou variabilidade para tolerância ao frio, no período vegetativo, enquanto para o período reprodutivo não foi obtida variabilidade suficiente para expressar tolerância.

\section{AGRADECIMENTOS}

Esta pesquisa foi realizada com recursos do Instituto Rio Grandense do Arroz (IRGA), Conselho Nacional de Desenvolvimento Científico e Tecnológico (CNPQ), Coordenação de Aperfeiçoamento de Pessoal de Nível Superior (CAPES), Fundação de Amparo à Pesquisa do Rio Grande do Sul (FAPERGS) e bolsas de produtividade em pesquisa dos professores Antonio Costa de Oliveira e Fernando Irajá Felix de Carvalho, bolsas de pós-graduação dos alunos, Andreza Figueirola Martins, Juliana Castelo Branco, Eduardo Alano Vieira, Mauricio Marini Kopp, e dos alunos de iniciação cientifica Viviane Kopp da Luz e Marcos Fontoura de Carvalho.

\section{REFERÊNCIAS}

ANDAYA, V.C.; MACKILL, D.J. Mapping of QTLs associated with cold tolerance during the vegetative stage in rice. Journal of Experimental Botany, Oxford, v.54, n.392, p.2579-2585, 2003.

BERTIN, P.; BOUHARMONT, J. Use of somaclonal variation and in vitro selection for chilling tolerance improvement in rice. Euphytica, Wageningen, v.96, n.1, p.135-142, 1997.

CRUZ, R.P. Bases genéticas da tolerância ao frio em arroz (Oryza sativa L.). 2001. Porto Alegre, 155f. Tese (Doutorado em Fitotecnia) - Programa de Pós-graduação em Fitotecnia, Universidade Federal do Rio Grande do Sul, 2001.
CRUZ, R.P.; MILACH, S.C.K. Melhoramento genético para tolerância ao frio em arroz irrigado. Ciência Rural, Santa Maria, v.30, n.5, p.909-917, 2000.

KHAN, D.R.; MACKILL, D.J.; VERGARA, B.S. Selection for tolerance to low temperature-induced spikelet sterility at anthesis in rice. Crop Science, Madison, v.26, n.4, p.694-698, 1986.

LI, C.C.; RUTGER, J.N. Inheritance of cool-temperature seedling vigor in rice and its relationship with other agronomic characters. Crop Science, Madison, v.20, n.3, p.295-298, 1980.

LIN, S.S.; PETERSON, M.L. Low temperatue-induced floret sterility in rice. Crop Science, Madison, v.15, n.5, p.657-660, 1975.

MACKILL, D.J.; COOFFMAN, W.R., GARRITY, D.P. Rainfed lowland rice improvement. Manila: Internacional Rice Research Institute, 1996. 242p.

MARTINS, A.F.; OLIVEIRA, A.C.; CARVALHO, F.I.F.; CRUZ, R.P.; VIEIRA, E.A.; KOPP, M.M.; CARVALHO, M.F.; TONIN,I.; MAIA,L. Caracterização de famílias de mutantes de arroz da cultivar BRS -7 para tolerância ao frio nos períodos germinativo, vegetativo e reprodutivo. In: CONGRESSO BRASILEIRO DE ARROZ IRRIGADO, 4., REUNIÃO DA CULTURA DO ARROZ IRRIGADO, 26., Santa Maria. Resumos... Santa Maria: SOSBAI, 2005. p. 86-88.

NISHIYAMA, I. Climatic influence on pollen formation and fertilization. In: TSUNODA, S.; TAKAHASHI, N. (Ed.). Biology of rice. Tokyo: Japan Scientific Societies Press, 1984. p.153-171.

SERAFIM, D.C. S. Mapeamento de QTLs para tolerância ao frio e características de importância agronômica em arroz. Porto Alegre, 2003. 68f. Dissertação (Mestrado em Fitotecnia) - Programa de Pós-graduação em Fitotecnia, Universidade Federal do Rio Grande do Sul., 2003.

SOUZA, P.R. Alguns aspectos da influência do clima temperado sobre a cultura do arroz irrigado, no sul do Brasil. Lavoura Arrozeira, Porto Alegre, v.43, n.389, p.9-11, 1990.

STEINMETZ, S. Influência do clima na cultura do arroz irrigado no Rio Grande do Sul. In: GOMES, A. S.; MAGALHÃES JUNIOR, A.M. (Ed.). Arroz Irrigado no Sul do Brasil. Brasília: Embrapa Informação Tecnológica, 2004. p.45-74.

STHAPIT, B.R.; WITCOMBE, J.R.; WILSON, J.M. Methods of selection for chilling tolerance in Nepalese rice by chlorophyll fluorescence anaysis. Crop Science, Madison, v.35, n.1, p.9094, 1995.

TERRES, A.L.; RIBEIRO, A.S.; MACHADO, M.O. Progress in breeding for cold tolerance semidwarf rice in Rio Grande do Sul, Brazil. In: TEMPERATURE RICE CONFERENCE. Yanco. Proceedings... Riverina: Charles Sturf University, 1994. p. 43-50.

TORIYAMA, K.; FUTSUHARA, Y. Genetical studies on the cool tolerance and other characters. Japanese Journal of Breeding, Tokyo, v.11, n.1, p.191-198, 1961.

YOSHIDA, S. Fundamentais of rice crop science. Los Baños: International Rice Research Institute, 1981. cap.1, p.1-63. 